\title{
Civil Liability for Damage Caused by Autonomous and Artificially Intelligent Robots
}

\author{
By \\ Dr. Elgamil S. Eladawi
}




\begin{abstract}
:
This research aims to determine who is liable before the law for the injuries that may be caused by AI machine or so-called "robot" which uses artificial intelligence (AI)'s technology established by the ability of mental trial and self-decision; However, since even the best technology is not error-free, robots may cause severe damage to human beings and property, for society to just accept these new technologies and to foster innovation, clear rules on civil liability are required.
\end{abstract}

The Legislature in the EU, US and MENA region have been cautious about this issue, which has shaped a thoughtful predicament in defining who is responsible for the actions of the robot, whether the robot itself is liable for it, or that it is in the future liable to accept its consequences, and then to hold the robot personally responsible for the harm it may cause.

After reviewing the European Civil Law of Robotics issued in February 2017, we found that the EU's resolution was based on the idea of a "Human Agent" was liable to compensate for the damage caused by the acts of the robot; manufacturers, operators or owners.

That means the robot may be given a legal status which allows it to be an enabler, not a safeguarded thing, and to establish a future 
legal status for the robot that may give it a legal personality, which necessitates studying the effect of the human Agent theory on the feasibility of the law in its traditional sense in the near future.

Keywords: Legal Personality, Legal Responsibility, Strict Liability, Negligence, Legal entity. 


\section{Introduction and Overview:}

\section{- Artificial Intelligence and the Liability Problem:}

Humankind has for millenniums dreamt of making an artificial being that acts humanly, in fiction as well as philosophically. This dream is close to coming true, perhaps already within this century. The rapid technological change in our world has increased the number of technology influencing our lives. For instance, some law firms have already hired their first artificially intelligent attorney. Our phones have artificially intelligent assistants that learn which applications we use the foremost, and where we are heading when starting the car's engine. Robotics nurses and surgeons aren't fiction anymore. However, AI is increasingly being used in daily life. Sometimes, people enjoy the benefits of AI without even realizing it (smart, self-training programs, such as Siri, bots, Drones, and Autonomous cars, etc.) We live within the age of artificial intelligence (“AI”).

AI can briefly be described because the science of creating machines intelligent, to be ready to perform tasks that generally require human intelligence. Driving a car, trading stocks at the stock market and defining a military target in war are examples for 
tasks that afore required human intelligence. Today, there are AIs ready to perform an equivalent task without human involvement.

AI technology often uses methods of reinforcement or machine learning to process big amounts of knowledge. An AI machine learns its task gradually to be more efficient and to become better; even as human - without further programming. Big technology companies are using AI alongside with reinforcement learning methods, to offer the user 'unique, personalized experiences'. In existing fields, AIs have demonstrated a surprising ability to require unforeseeable decisions. Numerous AIs have also been involved in accidents of deadly innocent people, where the decisions made by the AIs themselves are questionable. This has given rise to public concerns that damages caused by AI without any possibility to carry a person's liable.

However, since even the foremost effective technology isn't error-free and since the interaction between humans and robots increases; domestic robots, self-driving cars, and other autonomous systems can inevitably cause harm to people and property. It's up to a given society to easily settle for the new technologies, to foster innovation, and develop clear laws on civil liability are required. 


\section{- Law, robots and the Liability Problem:}

The prevalence of AI in society means more people use AI, the greater the likelihood of varied violations of law which require legal liability. Thus, AI development and its ever-growing practical use require an update to legal regulations, and essentially restructure the legal system. If artificial intelligence seems as planned, i.e. a thinking human-like robot with feelings and emotions, then the law has to be altered to encompass the roles of robots in society. It means the lawmakers must review the prevailing legal framework and adapt it to the changing need of society.

Furthermore, with advances in artificial intelligence (AI), and particularly with machine learning techniques which permit robots to find out from experience and to resolve problems using algorithms and perform sophisticated analytical techniques, robots became more and more self-determining from human superordinate management. Unlike several of the non-autonomous robots operational in our homes and factories, autonomous robots are ready to take a high-level goal and determine the way to achieve it. Often with little or no human supervision in the least. In fact, to some extent robots operating with machine learning techniques can 
find out how to unravel problems instead of having to be preprogrammed to perform each task.

Moreover, Robots with autonomy are generally ready to work for a short time independent of human intervention, navigate independently without human assistance, and avoid situations that will be harmful to the robot, people, or property. These characteristics of robots may cause self-maintenance, independent navigation throughout the environment, and therefore the learning required to perform tasks autonomously.

But with such robots, there is some problems for the law is that robots with machine learning, might not learn or reason as humans do, which can make their outputs difficult to predict, explain, and analyze underneath current legal schemes.

While the operation of autonomous robotic is typically regulated by the 2017 European Parliament resolution on Civil law rules on robotics, and therefore the US Chamber Institute for Legal Reform. In contrast with the Arabian region, ${ }^{(}$this type of topic remains has little to no attention of concern; no regulations reforms have been introduced as of yet. However, this technological development within the mid-east has not been determined by its 
legal features yet, therefore, we will refer to the general rules of civil law as much as possible, when it is needed.

\section{- Purpose Idea of the research and challenges:}

Robotics and AI became one of the foremost outstanding technological trends of our century. The fast increase in their use and development brings new and difficult challenges to our society. The road from the economic sector to the civil society environment obliges a distinct approach to these technologies, as robots and AI would increase their interaction with humans in diverse fields.

I believe that the danger posed by these new interactions ought to be tackled desperately, ensuring that a set of core fundamental values is translated into every stage of contact between robots, AI and humans. Such values to include human safety, privacy, integrity, dignity, and autonomy.

Whereas, because of the spectacular technological advances of the last decade, not only are today's robots ready to perform activities which used to be typically and exclusively be performed by human but the development of autonomous and cognitive feature - e.g. the capability to find out from expertise and take independent decisions - has made them more and more similar to agents that interact with their environment and are ready to alter it 
significantly; whereas, in such context, the necessity arising from a robot's harmful action becomes a big issue.

Accordingly, the liability for the damages caused by the actions of AI has some issues we have to deal with . Besides these legal regulations, a number of the most questions arise: is AI capable of causing damage (is it possible that AI could also be hazardous and may cause damage?) Can AI be held responsible for its actions? What is the legal regulation of damages caused by AI?

\section{- Research methodology and outline:}

Since machines have become highly automatized or maybe fully autonomous, the range of possible applications is staggering. However, since even the best technology is not error-free and because the interaction between humans and robots increases, domestic robots, self-driving cars and other autonomous systems will inevitably cause harm to people and property. Therefore, as for societies to simply accept new technologies and foster innovation, clear rules of civil liability are required.

In addition, since there are not any general laws specifically regulating autonomous systems, this research will aim to approach the question of liability through the comparison to the extension of traditional legal doctrines. Hence, this research will discuss how 
traditional civil liability theory doctrine within the EU, US, and Egypt are often applied to autonomous robots and compares current legal approaches to the present issue in these different types of jurisdictions.

This research proceeds as follows. In chapter 1, it reviews the Legal Personality for Autonomous and artificially intelligent robots are going to be essential or inessential. The review will cover the issue of whether AIs and autonomous robots should have a legal entity with legal rights and personal liability to be held liable for its actions or that legal rights and liabilities should not be extended to cover AI and autonomous robots. In chapter 2, discusses the legal personality of AI and autonomous robots to define the purpose of civil liability and to identify the party responsible for reparation of the infringement of another party's rights or interests. 


\section{Chapter 1}

\section{Legal Personality for Autonomous and Artificial Intelligence Robots}

There is no doubt that Artificial Intelligence is becoming more and more involved in our daily lives. AI is not limited to a particular form, it ranges from the use of Siri to make a simple phone call, to the use of security cameras with facial recognition technology universally as a way to track individuals. AI was at the beginning created to carry out tasks that might be tedious for human beings to do, such as seen within the scenario of working at manufacturing lines in factories. AI is said to be very effective as it can essentially carry out the same work that one single person could do many times faster. The result is higher productivity levels, and lower labor costs. Over time, the designers of AI became more creative and decided to develop AI's abilities to include more complex activities such as speech recognition, learning, planning, and problem-solving.

- The Incongruousness of creating robots as liable legal persons:

The idea of AI outperforming humans in all kinds of task is spectacular to some but also worrying to others. Therefore, the 
current incongruousness regarding the legal entity of AI are split between two schools of thoughts as follows:

The first school believes that because the potential of AI to surpass human intelligence grows higher, AI ought to be granted its legal rights and be subject to its liabilities. This school believes that AI ought to be treated as a legal person regarding the thought of "corporate personhood", just like however the corporation is granted standing as a legal person with its rights and duties.

And the second school believes that legal rights and liabilities mustn't be extended to cover AI as AI is just the results of programming by personalities so all of its actions may be derived back to either a personality's being or a corporation. In alternative words, this school argues that AI does not have total autonomy as everything they are doing is barely as a result of they were programmed to try and do this at the start, and not as a result of they are acting upon their powerfulness.

Based on the second school opinion and refer to Article 59 (f) calls upon the European Commission to explore the legal consequences of planned making a new category of individuals, specifically for robots: electronic persons. 
Therefore, traditionally when assigning an entity legal personality, we seek to assimilate it to humankind. This can be the case with animal rights, with advocates' argument that animals ought to be appointed a legal temperament since some are acutely aware beings, capable of suffering, etc., and so feeling which separates them from things. Yet the recommendations to the commission on civil law rules on artificial intelligence do not tie to the acceptance of the robot's legal temperament to any potential consciousness.

Legal temperament is there for not coupled to any regard for the robot's inner being or feeling, avoiding the questionable assumption that the robot could be aware of being. Assigning robots such temperament would, then, meet a simple operational objective arising from the requirement to create robots responsible for their actions.

There is one completely different situation once it ought to be attainable to assign associated entity legal personality: once this assignment would grant it a legal life. Thomas Hobbes informs the U.S. in Léviathan that the word "person" (persona) comes from the Latin for the mask, later returning to represent the self or the opposite. The "legal person" construct illustrates that the law has already appointed legal temperament to a non-human entity. 
However, it might not be right to assume from this that robots may additionally get pleasure from such a temperament.

Legal personality is appointed to a natural person as a natural consequence of their being human; in contrast, its assignment to a legal person is relying on a legal fiction. A Legal person's square measure ready to act among the legal sphere entirely as a result of there is a temperament being behind the scenes to represent it. Ultimately, it is, then, a physical person that breathes legal life into a legal person and without which, the latter could be a mere empty shell. That being the case, wherever will we stand with the robot? We've options: either a physical person is that the true legal actor behind the automaton or the robot itself can be a legal actor.

On the one hand, if we tend to deem there to be somebody behind the autonomous automaton, then this person would represent the electronic person, which, lawfully speaking, would just like the legal person - simply be a fictional intellectual construct. That aforesaid though, the thought that one might develop such a classy mechanism to provide such a pointless result shows however incongruous it'd be to assign legal temperament to what is simply a machine. 
On the opposite hand, the European Parliament resolution would seem additionally inclined to completely erase the human presence. In viewing as an associated degree electronic person, any "robots [which] build sensible autonomous decisions or otherwise act with third parties" (end of Article 59 (f)), the resolution appears to suggest that the automaton itself would be liable and become a legal actor. This analysis finds support in Article $A B$ of the European Commission resolution, that states as below. Once an automaton is not any longer controlled by another actor, it becomes the actor itself. however will a mere machine, a body innocent of consciousness, feelings, thoughts or its can, become an autonomous legal actor? However, will we tend to even conceive this reality as foreseeable with 10 to 15 years, i.e. within the time frame set in Article 6 of the European Commission resolution from a scientific, legal and even moral perspective, it's not possible these days- and possibly will remain so far a long time to come - for a robot to take part in legal life without a human being pulling its strings.

What is loads of, considering that the most purpose of assignment a robot legal personality would be to create it a liable actor within the event of injury, we should not that other systems would be way more effective at compensating victims; for example; 
an insurance theme for autonomous robots, maybe combined with a compensation fund, (Article 59(a) to (e)).

In reality, advocates of the legal personality possibility have a fantastic vision of the robot, inspired by science-fiction novels and cinema. They browse the automaton - significantly if it's classified pretty much as good and robot - as a true thinking creation, humanity's friend, we tend to believe it would be inappropriate and out-of-place not solely to acknowledge the existence of an electronic person however to even produce any such legal personality. Doing, therefore, risks not exclusively assignment rights and obligations to what's merely a tool, however additionally demolishing the boundaries between man and machine, blurring the lines between the living and also the inert, the human and inhuman.

Moreover, creating a substitution type of a person - associated degree electronic person - sends a powerful signal that couldn't solely light the worry artificial being however additionally decision into question generally humanist foundations. The assignment person standing to a non-living, non-conscious entity would, therefore, be an error since, in the end, humankind would probably be demoted to the rank of a machine. Robots need to serve humanity and not have any different role, except inside the realms of fantasy. 
On the other side, there is another opinion advocated by the first school, which considering the AI ought to have a legal entity with legal rights and personal liability, for the reason that AI will independently think on their own without the necessity of imitating human inputs or pre-programmed information ought to be considered as an entity. This is often as a result of they are independent and want if its legal entity since the laws that we have got now could be not sufficient to support AI capability to reason and perform by itself as a unique identity.

Thus, a singular legal entity with rights and liability square measure necessary for the implementation of AI. However, they cannot possess constant rights or liability as a natural person or legal person can since each of them is exclusive to every alternative. However before we tend to seek after the intent to expand legal rights to AI, we must always take a step back and look at another legal entity that's not entirely human, a legal person. A legal person may be a legal entity assortment of the person to be able to perform legal actions as a unique identity for various functions.

A legal person is entitled to legal protection of its rights and duties, except for some that may only be enjoyed or incurred by a natural person. This concept will suit the implementation of AI, 
which is additionally a legal entity. An example of this is the possession of properties. Even if a legal person cannot physically acquire its property, this could be done by its representative. The legal mechanism concerning a legal person can be implemented on AI since each of them does not have a physical existence, however, each of them exists within the legal realm. All the constraints on the rights and capabilities of the legal persons concerning legal actions that only a real person will perform may also be implemented for AI.

These actions area unit physically and lawfully reserved for a natural person, like the vote in elections, marriage, and inheritance. That means legal person will receive the inheritance because it will own property, this mechanism ought to be applied to AI too. Moreover, some countries develop a legislative base for a robotic, to explore the most options informative the legal personality of the AI, that arranged right down to instrument a framework of legal relations fashioned by legal entities. At the same time, there area unit some cases considering the robots as a standing national legal entity.

As a legal person, the AI would have a legal standing to sue and be sued. Current practices have already discovered that legal personality has been conferred to non-sentient entities like maritime 
vessels or company entities, for the sake of legal uniformity. However, we have never associated or expected such entities to possess human qualities or morality. Therefore, giving AIs legal entity bypasses all the ethical implications encompassing the growth of AIs rights. Making a legal identity for AIs would facilitate the correct allocation of rights; create to the rights that area unit suited to the AI instead of to project human-based rights on to the AI. This technique additionally acknowledges an AI's autonomy, as each activity conducted by the AI are within the name of the AI, and not its creators. Additionally, we can overcome the trouble of distinguishing the various owners of the elements of the AI; because the creators can jointly be thought to be the agents of the AI.

Lastly, civil liability problems also are resolved because of the presence of human beings; the agents (the AI's creators) should act on behalf of the AI and compensate the injured person. 


\subsection{Conclusion:}

In my opinion, I am inclined to agree with the second school of thought (AI must not have its legal rights and liabilities) for the subsequent reasons.

The first school of thought argued that corporations exist on paper as a separate legal entity from its administrators and shareholders. Even though corporations do not exist within the physical world (because it lacks a physical body), they are subject to their legal rights and duties and might be held liable for their actions. On the opposite hand, AI might or might not have a physical body however; it does indeed exists within the physical world and thus ought to be given the status of legal persons under the law.

I would prefer to point out that while a company exists as a separate legal entity and might be responsible for its actions, the action that a company takes should be carried out by a representative of the corporation. Thus, there is no doubt that there is indeed someone else (person) acting on its behalf. The same cannot be previously mentioned for AI that has no representative acting on its behalf, however, it's instead, and acting based on the commands that area unit programmed into it. If we tend to give 
rights to AI, this would lead to the question of whether or not the rights area unit given ought to be an equivalent as those given to natural persons or legal persons, however as mentioned earlier, it should not run an equivalent rights as a legal person because it's not acting within the same way. Legal persons will be held responsible instead of its administrators however the same concept should not apply to AI and its creators because it might provide an incentive for people (such as the individuals or corporations liable for the manufacture of $\mathrm{AI}$ ) to flee both contractual and tort liability.

For example, within the case of using robotic surgeons to control patients, if one thing was to go wrong, the conception of AI having sole liability for the accident seems absurd because AI can't be physically held in a jail cell or forced to pay a fine. In addition, AI and other robots cannot be sued nor will they be subject to many serious procedures of criminal punishments like facing death penalties. By granting AI with its rights and liabilities, this would allow for the individual or corporation who created the robotic surgeon to flee the responsibility by using AI as a defend to safeguard them from the law.

Thus, since civil and criminal liabilities do not affect AI, the people behind them ought to be held liable instead. By holding each natural person and legal persons liable for the actions of AI that 
they need to be created, this would allow for the fulfillment of the aim of the law, which means that the injured party will be able to exercise the right of recourse and therefore the right to receive compensation. Furthermore, if the liabilities and penalties under the law do not affect AI, the law would be useless, and it might not be doing its job of imposing the rights and obligations of parties.

In conclusion, although it is going to seem unfair to place the fault on the creator of AI, it ought to be noted that at the end of the day, someone ought to be responsible for any errors made. In addition, by putting limits on the recognition of $\mathrm{AI}$ as legal persons, this serves to bring us a level of security. Whenever a corporation does a specific act, we all know for evidently that there is a person behind the scenes who are pulling the strings even if the corporation is its own "person" within the eyes of the law. However, the equivalent reassurance cannot be previously mentioned for $\mathrm{AI}$ if we tend to recognize it as a person. 


\section{Chapter 2}

\section{Civil Liability for Autonomous and Artificial Intelligence Robots}

\section{- Basic Legal Structure:}

The High volume of daily commercial transactions in the economic environment globally and locally requires protection by the law to the interest of damaged parties due to breaching of agreements concluded between them. Therefore, the Egyptian Law defined that civil liability as the obligation to compensate for the damage caused by a breach of the original obligation, the original obligations arising from the contract, and others from the law.

Such civil liability may be due to a contractual relationship or due to a non-contractual "tort". The Egyptian Civil Code regulates tort liability for damages to third parties in Articles 163 to 178. The Liability either be of personal act, which is regulated in Articles 163 to 172 , or liability for others' act which is regulated in Articles 173 to 175 and liability for damages of things that has to be guarded regulated in Articles 176 to 178. According to the Law, the damaged party of the aforementioned liabilities are entitled for compensation. 
As mentioned before, the civil liability is divided into contractual or non-contractual liability. The first is that the obligation arising from the contract in case of not implementing the contract in the agreed manner. While the non-contractual or tort liability is based on a legal obligation derived from the provisions of the law, to compensate the injured person without a contractual relationship for example, the responsibility of the driver of the vehicle to injuring a passerby or killing him or the neighbor's responsibility for the demolition of the neighboring house during the restoration of his home.

However, The purpose of civil liability is to recognize the party liable for reparation of the infringement of another party's rights or interests. It may be a matter of "contractual" or "noncontractual" liability. Contractual liability arises once though damage doesn't occur, a robot doesn't conform to contractual obligations, e.g. doesn't have the promised features. Noncontractual liability arises once associate agent, in this case, a robot, causes damage due to violation of a right, which is lawfully protected regardless of the existence of a contract (e.g. physical integrity).

Contractual liability is disciplined by the Principle of European Contract Law (PECL). Under Article 1:301 of PECL, 
'non-performance' is qualified as "any failure to perform an obligation under the contract, whether or not excused, and includes delayed performance, defective performance and failure to cooperate in order to give full effect to the contract". The article specifically states that an 'intentional' act includes an act carried out recklessly.

After a general part dedicated to formation of contract, validity and other legal rules, Chapter 8 examines non-performance and remedies. Non-performance is fundamental (Article 8:103 PECL) if: (a) strict compliance with the obligation is of the essence of the contract; or(b) the non-performance substantially deprives the aggrieved party of what it was entitled to expect under the contract, unless the other party did not foresee and could not reasonably have foreseen that result; or(c) the non-performance is intentional and gives the aggrieved party reason to believe that it cannot rely on the other party's future performance.

Article 8:108 PECL disciplines non-performance which cannot be attributed to a debtor: A party's non-performance is excused if it proves that it is due to an impediment beyond its control and that it could not reasonably have been expected to take the impediment in to account at the time of the conclusion of the contract, or to have avoided or overcome the impediment or its 
consequences. However, clauses limiting or excluding remedies for non-performance are acceptable if their content is not contrary to good faith and fair dealing (Article 8:109).

The Egyptian Civil Code discusses various sources of obligations, the most important of which for present purposes are contract and tort. The applicable Egyptian legal provisions are quite similar to those prevailing in most European civil law jurisdictions. In general, a claim for compensation under the Egyptian Civil Code, unlike the law in some other Arab jurisdictions, must be based on either contractual or tort liability. In other words, a plaintiff may not base its claim against a defendant on a combination of the two types of liability. Where a contract exists, a contractual party seeking compensation for harm suffered generally must proceed under contract principles.

\section{- Damage:}

The main purpose of tort law is to indemnify victims for losses they should not have to bear themselves entirely based on an assessment of all the interests involved. However, only compensable harm will be indemnified, meaning damage to a limited range of interests that a legal system deems worthy of protection. 
Article 221 of the Egyptian Civil Code contains some general principles for quantifying damages resulting from breach of an obligation, whether arising under contract or tort. (The Civil Code often refers to the party breaching its obligation as the 'debtor', and the party suffering harm from that breach as the 'creditor'.)

- The judge will determine the amount of damages, if it has not been established within the parties' contract (e.g., a liquidated damages clause) or by law.

- The amount of damages shall include losses suffered by the creditor as well as lost profits, provided such are the normal result of the debtor's failure to perform its obligation (or its delay in performing). For these purposes, such losses shall be considered to be a 'normal result' if the creditor is not able to avoid those losses despite making reasonable efforts.

- If the relevant obligation arises from contract (rather than tort) principles, then a debtor will not be liable for damages greater than what could have been normally foreseen at the time of entering into the contract - although this limitation does not apply if the debtor committed fraud or gross negligence. 
While there is unanimous accord that injuries to a person or to physical property can trigger tortious liability, this is not universally accepted for pure economic loss. Damage caused by self-learning algorithms on financial markets, for example, will therefore often remain un-compensated, because some legal systems do not provide tort law protection of such interests at all or only if additional requirements are fulfilled, such as a contractual relationship between the parties or the violation of some specific rule of conduct. Nor is it universally accepted throughout Europe that damage to or the destruction of data is a property loss, since in some legal systems the notion of property is limited to corporeal objects and excludes intangibles.

In addition, The Egyptian Civil Code contains some other rules on damages that apply specially to either contractual liability or tortious liability, but not both. For example, contractual parties may agree in advance as to "liquidated damages" owed in the event of contractual breach. Articles 224 and 225 of the Egyptian Civil Code contain three important general principles:

- the liquidated amount is not owed if the debtor proves that the creditor did not suffer any damage; 
- the liquidated amount may be reduced if the debtor proves that the parties' estimation was excessive, or if the debtor has partly performed the contractual obligation; and

- the creditor is not entitled to claim more than the liquidated damages, even if harmed in excess of the liquidated amount, unless the debtor has committed fraud or gross error.

Other differences exist when it comes to the recognition of personality rights, which may also be adversely affected by emerging digital technologies, if certain data is released which infringes on the right to privacy for instance.

However, generally speaking, AI technologies do not call into question the existing range of compensable harm. Rather, some of the already recognized categories of losses may be more relevant in future cases than in traditional tort scenarios. Damage as a prerequisite for liability is also a flexible concept - the interest at stake may be more or less significant, and the extent of damage to such an interest may vary. This may in turn have an impact on the overall assessment of whether or not a tort claim seems justified in an individual case. 


\section{- Causation:}

One of the most essential requirements for establishing liability is a causal link between the victim's harm and the defendant's sphere. As a rule, the victim who must prove that their damage originated from some conduct or risk attributable to the defendant. The victim then needs to produce evidence in support of this argument. However, the less evident the sequence of events was that led to the victim's loss, the more complex the interplay of various factors that either jointly or separately contributed to the damage, the more crucial links in the chain of events are within the defendant's control, the more difficult it will be for the victim to succeed in establishing causation without alleviating their burden of proof. If the victim fails to persuade the court, to the required standard of proof, that something for which the defendant has to account for triggered the harm they suffered, they will lose their case, regardless of how strong it would have been against the defendant otherwise (for instance, because of evident negligence on the defendant's part).

Tough as it is to prove that some hardware defect was the reason someone was injured, for instance, it becomes very difficult to establish that the cause of harm was some flawed algorithm. 
Illustration 1. If a smoke detector in a smart home environment fails to trigger an alarm because of flawed wiring, this defect may be identifiable (and in this case is even visible). If, on the other hand, the smoke detector did not go off because of some firmware error, this may not be proven as easily (even though the absence of an alarm per se may be easily proven), if only because it requires a careful analysis of the firmware's code and Its suitability for the hardware components of the smoke detector.

It is even harder if the algorithm suspected of causing harm has been developed or modified by some AI system fuelled by machine learning and deep learning techniques, because of multiple external data collected since the start of its operation. Even without changes to the original software design, the embedded criteria steering the collection and analysis of data and the decision-making process may not be readily explicable and often require costly analysis by experts. This may in itself be a primary practical obstacle to pursuing a claim for compensation, even if those costs should ultimately be recoverable as long as the chances of succeeding are hard to predict for the victim upfront.

There are certain characteristics of autonomous systems that separate them from "normal" machines and create specific problems for determining liability. The most crucial factors are 
deep learning (especially reinforcement learning), mobility, interconnectedness, and the (un)foreseeability of the intelligent machines. Robot learning describes the robot's ability to improve its performance through practice.

The relevant information for learning processes stems from existing data, but also from experiences and other new information. The relevant aspect of this technological development is the decrease of human control, seeing as deep learning can function solely by relying on training by algorithms without human intervention ("unsupervised learning"). Besides, the rising interconnectedness of machines can cause problems, since they are capable of simultaneously developing a connected infrastructure, making the isolated treatment of a single system more complicated. Lastly, the unforeseeable actions of autonomous systems might constitute the greatest challenge for traditional liability systems. The more intelligent systems learn independently and from other connected systems, the more difficult it can be for the human user to foresee robot behavior.

Whereas autonomous acts by a robot could be handled by a regime of strict liability, no member state in the EU nor any state in the US has enacted a statute specifically for damage done by intelligent robots. According to an EU study, liability for damages 
caused by objects is generally attributed to the persons who have the object under their care or custody (listing Belgium, the Czech Republic, Estonia, and Luxembourg as examples). One exception is France, where the custodian's liability without fault is explicitly applicable to any kind of object that causes damage.

In the US, the regime of strict liability governs product liability, the liability of the owner of wild animals and therefore the liability for abnormally dangerous activities. In light of this framework, researchers and organizations have made suggestions for future changes of the liability systems, as well as but not restricted to the introduction of a new strict liability statute for the possessors or operators of the intelligent robotic machines.

Furthermore, the European Parliament considers two possible approaches as possible solutions: (1) a strict liability regime or (2) a risk management approach. The strict liability approach would help the injured party since it only needs proof that harm has occurred which a causative link existed between the robot's action and also the injury. A risk management approach would, on the opposite hand, find liable the person who would have been able to minimize the risk, that isn't essentially the person "who acted negligently". 
On the other side, there are fundamental differences between the U.S and Egyptian legal systems. The Egyptian legal system (including its judicial structure and procedures, as well as its substantive laws) is largely a civil law system, along the lines of European continental civil law systems. Product liability lawsuits brought before the Egyptian courts involve civil law concepts of contractual and tort liability, with the judge determining both questions of law and assessment of fact -- juries are not a feature of the Egyptian judicial system. Similarly, the U.S. legal concept of punitive damages (i.e., awards that exceed a private party's actual damages suffered) does not exist in Egypt, and class action lawsuits are not a prominent feature of the Egyptian judicial system.

Overall, the liable party ought to solely be liable "proportional to the particular level of directions given to the robot" - the higher the robot's learning capabilities are, or the longer duration of the robot's education, the greater the obligation of the user/owner.

Additionally, there area unit some possible analogies regarding the liability of the user exist within the EU as well as within the US. Among the foremost common theories area unit the liability of owners for their animals, the liability of parents for their kids, the liability of employers for their workers, and the responsibility for persons carrying out unusually dangerous 
activities. Any possible framework should balance various related concerns, like the specific risks of robots, present legal standards, and consumer protection goals.

The focus lies on liability without fault, since the regular of care in the realm of negligence may become unfulfillable if the courts continuously form new duties of care and obligations for superintendence and management. At some point, such a development would be equal to a strict liability statute. In sum, the analogy to existing theories or the implementation of a special strict liability regime may be favorable and would at least create a degree of legal certainty.

In cases of strict liability, proving causation may be easier for the victim and not only in those jurisdictions where causation is presumed in such cases. Instead of establishing some misconduct in the sphere of the defendant, the victim only has to prove that the risk triggering strict liability materialised. Depending on how this risk was defined by the legislator, this may be easier, considering that, for instance, current motor vehicle liability statutes merely require an 'involvement' of the car or its being 'in operation' when the accident happened. 
In addition to the initial complexity of AI systems upon announcement, the victims can seek damages claims against the manufacturer. In most countries, defective products laws repute manufacturers liable for harm caused by the products they bring to markets. A product is typically deemed defective when it generates unpredicted injury in normal use. In turn, a defect is assessed in normal circumstances of use that is "use to which it could reasonably be expected that the product would be put". Most defective products law establish a strict liability regime: the mere proof of a defect triggers liability, regardless of whether there has been fault or negligence. And defective product laws tolerate only a limited number of exoneration causes. This kind of liability relies on the causation of a certain risk rather than on a specific action itself. outside of product liability law (which is strict), extracontractual liability legislation is not entirely harmonized in the EU. and they will most likely be subject to more or less numerous upgrades, which are not essentially supplied by the original manufacturer. Categorizing which part of a now flawed code was wrong from the launch or harmfully changed in the course of an update, will at least require (again) significant expert input, but doing so is essential in order to determine whom to sue for compensation. 
The procedure of AI systems often depends on data and other input collected by the system's own sensors or added by external sources. Not only may such data be damaged in itself, but the processing of otherwise correct data may also be imperfect. The latter may be due to original defects in designing the handling of data, or the consequence of distortions of the system's self learning capabilities due to the substance of data collected, whose randomness may lead the AI system in question to misperceive and miscategorise subsequent input.

Complications of uncertain causation are of course not new to European legal systems, even though they are posed differently depending on the applicable standard of proof. As long as the uncertainly exceeds that threshold, the victim will remain uncompensated, but as soon as the likelihood of the causation theory on which the victim's case rests meets the standard of proof, they will be fully compensated.

This all-or-nothing predicament is already being addressed throughout Europe by some modifications that aid the victim in proving causation under certain conditions. Courts may for instance be willing to accept prima facie evidence in complex scenarios, such as those emerging digital technologies give rise to, where the exact sequence of events may be difficult to prove. While the 
burden of proving causation is not shifted yet, it is clearly eased for the victim, who need not substantiate every single link in the chain of causation if courts accept that a given outcome is the typical effect of a certain development in that chain. Moreover, as past medical misconduct cases have shown, courts tend to be willing to place the burden of producing evidence on the party who is or should be in control of the evidence, with failure to bring forward such evidence resulting in a presumption to the detriment of that party.

If for instance, certain log files cannot be produced or properly read, courts may be arranged to hold this against the party that was in charge of these recordings (and/or of the technology for analysing them). In some cases, some European legislators have occurred and shifted the burden of proving causation altogether, thereby presuming that the victim's harm was caused by the perpetrator, though leaving the perpetrator the possibility to rebut this. It remains to be seen to what extent any of these tools will be used in favour of the victim if their harm may have been caused by the autonomous robots.

It is already difficult to prove that some behavior or activity was the cause of harm, but it gets even more complex if other substitute causes come into play. This is nothing new, but it will 
become much more of an issue in the future, given the interconnectedness of emerging AIs and their increased dependency on external input and data, making it increasingly doubtful whether the damage at stake was caused by a single original cause or by the interplay of multiple (actual or potential) causes.

Current tort law regimes in Europe handle such doubts in the case of multiple potential sources of harm quite differently. Even if something is proven to have caused the harm (for instance, because an autonomous car hit with a tree), the real reason for it is not always similarly obvious. The car may have been poorly designed (be it its hardware, pre-installed software, or both), but it may also have either misread correct, or received incorrect, data, or a software update done by the original producer or by some third party may have been damaged, or the operator may have unsuccessful to install an update which would have prevented the impact, to give just a few examples, not to mention a combination of multiple such factors.

The standard response by existing tort laws in Europe in such cases of substitute causation, if it remains unclear which one of several possible causes was the decisive influence to cause of the harm, is that either no-one is responsible (since the victim's evidence fails to reach the threshold to prove causation of one 
cause), or that all parties are equally and separately responsible, which is the common view.. The former outcome is detrimental for the victim, the latter for those merely possible tortfeasors who in fact did not cause harm, but may still be attractive targets for litigation because of their procedural availability and/or their more promising financial ability to actually pay compensation. The problem of who really caused the harm in question will therefore often not be solved in the first round of litigation started by the victim, but on alternative level, if ever. Approaches that are more modern provide for comparative liability at least in some cases, reducing the victim's claim against each potential tortfeasor to allowance corresponding to the possibility that each of them in fact caused the harm in question.

\section{- Wrongful acts and omission:}

As the principal provision of tortious liability, Article 163(1) of the Civil Code stipulates that any person that intentionally or negligently causes damage or injury to another person is liable to the injured party for compensation. Article 163(1) of the Civil Code explicitly comprises three conditions:

- act or omission;

- damage or injury; and 
- a causal link between the two.

However, it is generally understood that a person will be considered liable under Article 163(1) of the Civil Code only where and insofar as it was at fault.

The Civil Code does not comprise a statutory definition of 'fault'. The definition generally used in Egyptian law today is the one introduced by the Court of Cassation in 1978, which defined 'tortious fault' as conduct that deviates from the norm, insofar as it ignores the care and prudence that an average reasonable person would observe. This definition describes what is commonly understood as negligence. While the Court of Cassation did not explicitly include intent in its definition of 'tortious fault', there is consensus that tortious fault under Egyptian law comprises intent. Thus, as a fourth implicit element of claim, Article 163(1) of the Civil Code requires that the obligor acted - or failed to act intentionally or negligently.

Consideration must also be given to liability for omissions. If such liability were to be imposed without further restrictions, the group of persons potentially liable under Article 163(1) of the Civil Code would be overly extensive. For instance, an innocent bystander could be held liable for failing to prevent a person from 
using an obviously unsafe product. Therefore, some jurisdictions have limited tortious liability for omissions to situations where the concerned person was under a duty to act (ie, a driver involved in a car accident being obliged to assist other persons involved in the accident). However, Egyptian law does not apply this method, but rather solves the issue through the requirement of fault. Thus, when deciding on whether a person is liable for failing to prevent harm to another person, an Egyptian court will consider whether the harm was caused due to this failure.

As any person causing damage or injury is liable under Article 163(1) of the Civil Code, the manufacturer or distributor of a product may be held liable pursuant to Article 163(1) of the Civil Code where:

- a defect in the good caused harm to a person; and

- the defect was caused, intentionally or negligently, by the manufacturer or distributor.

Thus, in contrast to liability under Article 67(1) of the Commercial Transaction Law, a person (eg, the manufacturer or distributor of goods) may be liable for a defect only if that person was responsible for causing the defect. Due to this requirement, distributors - which may be held liable for production defects under 
Article 67(1) of the Commercial Transaction Law - will not be liable for production defects under Article 163(1) of the Civil Code, since they are unlikely to be responsible for a production defect in the product being sold. However, distributors may be liable for defects caused by improper storage or handling of goods pursuant to Article 163(1) of the Civil Code - defects for which a manufacturer will likely not be liable.

Unlike contractual liability, liability under Article 163(1) of the Civil Code is not restricted to specific persons. Any injured party can recover damages under tort.

The injury or damage incurred need not be foreseeable in order to be recoverable under tortious liability. Still, as a general principle of Egyptian law, consequent damages are recoverable under tort only where they were a natural consequence of the wrongful act or omission. Thus, tortious liability is wider than contractual liability insofar as it does not restrict the injured party to compensation for foreseeable damage or injury, but does not necessarily cover responsibility for all consequential damages.

Actions under Article 163(1) of the Civil Code are time barred three years from the date on which the obligee become aware of the 
elements of claim and, in any case, 15 years after the wrongful act or omission occurred (Article 172 of the Civil Code).

Pursuant to Egyptian law, liability under tort may not be limited or excluded by agreement. Any agreement to the contrary is void (Article 217(3) of the Civil Code).

In addition to what already mentioned in the overview above, tort laws in Europe are traditionally fault-based, providing compensation to the victim if the defendant is to blame for the former's damage. Such blame is commonly linked to the deviation from some conduct expected of, but not shown, by the tortfeasor. Whether or not a legal system distinguishes between objective or subjective wrongdoing and/or divides the basis of liability for misconduct into wrongfulness and fault, two things remain crucial: to identify the duties of care the perpetrator should have discharged and to prove that the conduct of the perpetrator of the damage did not discharge those duties.

The duties in question are determined by various factors. Sometimes they are defined earlier by legal language prescribing or prohibiting certain specific conduct, but often they must be reconstructed after the fact by the court on the basis of social 
beliefs about the cautious and reasonable course of action in the conditions.

Emerging AIs technologies make it difficult to apply faultbased liability rules, due to the lack of well-established models of proper functioning of these technologies and the possibility of their developing because of learning without direct human control.

The processes running in $\mathrm{Al}$ systems cannot all be measured according to duties of care designed for human conduct, or not without adjustments that would require further explanation. As European legal systems tend to regulate product and safety requirements in advance more than other jurisdictions, it may well be the case that at least certain minimum rules will be introduced (if only, for example, logging requirements alleviating an analysis, after the fact, of what actually happened), to help define and apply the duties of care relevant for tort law should damage occur. A violation of such statutory or regulatory requirements may also trigger liability more easily for the victim, by shifting the burden of proving fault in many systems for instance. Still, such requirements will not be present from the beginning, and it may take years for such rules to emerge, either in legislation or in the courts. 
Legal requirements have to be distinguished from industry standards (or practices) not yet recognised by the legislator. Their relevance in a tort action is necessarily weaker, even though the courts may look at such requirements as well when assessing in review whether or not conduct complied with the duties of care that needed to be discharged under the circumstances.

Taking a step back and shifting the focus onto a software developer who wrote the firmware for some smart gadget, for instance, does not resolve the problem entirely, since - as already mentioned - the software may have been designed to adjust itself to unprecedented situations or at least to manage with novel input not matching any pre-installed data. If the operation of some technology that includes $\mathrm{AI}$, for instance, is legally permissible, presuming that the developer made use of state-of-the-art knowledge at the time the system was launched, any subsequent choices made by the AI technology independently may not necessarily be attributable to some flaw in its original design. The question therefore arises whether the choice to admit it to the market, or implement the AI system in an environment where harm was consequently caused, in itself is a breach of the duties of care applicable to such choices. 
In addition to the difficulties of determining what constitutes fault in the case of damage caused by an emerging digital technology, there may also be problems with proving fault. In general, the victim has to prove that the defendant (or someone whose conduct is attributable to them) was at fault. The victim therefore not only needs to identify which duties of care the defendant should have discharged, but also to prove to the court that these duties were breached. Proving the defendant is at fault entails providing the court with evidence that may lead it to believe what the applicable standard of care was and that it has not been met. The second part of this is to provide evidence of how the event giving rise to the damage occured. The more complex the circumstances leading to the victim's harm are, the harder it is to identify relevant evidence. For instance, it can be difficult and costly to identify a bug in a long and complicated software code. In the case of AI, examining the process leading to a specific result (how the input data led to the output data) may be difficult, very time-consuming and expensive.

\section{- Vicarious liability:}

Vicarious liability - that is, the liability for damage or injury caused by third parties - is governed by Article 173 and following of the Civil Code. Article 174 of the Civil Code stipulates that a 
person is liable for harm caused by the wrongful acts or omissions of third parties, if such harm was caused in execution of a task for which the third party was retained by the obligor. Thus, under Article 174 of the Civil Code, a manufacturer or distributor may be held liable for the actions or omissions of, among other things, an Egyptian commercial agent retained to sell his or her products in Egypt. However, the manufacturer or distributor can recover any compensation paid pursuant to Article 174 of the Civil Code from the third party (Article 175 of the Civil Code).

Liability for harm caused by an object (i.e. custodial liability) is regulated in Article 176 and following of the Civil Code. While Articles 176 and 177 of the Civil Code deal with liability for harm caused to animals and buildings (which will be of little relevance in respect of product liability), Article 178 of the Civil Code concerns liability for inanimate movable objects. It provides that a person who is charged with supervising an object (i.e. the custodian) will be liable for injury or damage caused by that object to another person. Since manufacturers and vendors usually do not have custody of goods after they are handed over to the buyer, this provision will have little application regarding product liability. However, liability under Article 178 of the Civil Code is strict. 
Existing tort laws in Europe differ substantially in their approach to holding someone (the principal) liable for the conduct of another (the auxiliary). Some attribute an auxiliary's conduct to the principal without further requirements, other than that the auxiliary acted under the direction of the principal and for the benefit of the principal. Others hold the principal liable in tort law only under very exceptional conditions, such as known dangerousness of the auxiliary or the auxiliary's complete unsuitability for the assigned task, or if the defendant was at fault in selecting or supervising the auxiliary. There are also jurisdictions, which use both approaches.

Jurisdictions with a neutral (and therefore broader) definition of strict liability (as liability without fault of the liable person in general) regard vicarious liability as a mere variant of this strict (or no-fault) liability. If the notion of strict liability is equated with liability for some specific risk, dangerous object or activity instead, vicarious liability is rather associated with fault liability, as liability of the principal without personal fault of their own, but for the (passed-on) 'fault' of their auxiliary instead, even though the auxiliary's conduct is then not necessarily evaluated according to the benchmarks applicable to themselves, but to the benchmarks for the principal. 
Regardless of such differences, the concept of vicarious liability is considered by some as a possible catalyst for arguing that operators of machines, computers, robots or similar technologies should also be strictly liable for their operations, based on an analogy to the basis of vicarious liability. If someone can be held liable for the violation of some human helper, why should the beneficiary of such support not be equally liable if they outsource their duties to a non-human helper instead, considering that they equally benefit from such delegation.

A victim can claim to engage the vicarious liability of a third party with omission. For simplicity, I call this third party a "governor". Common examples include the vicarious liability of employees, parents, masters, and owners, for damage caused respectively by employees, children, slaves, and property. As far as AIs are concerned, the governor of an algorithm's machines could be held liable for damages. In both civil and common law, indirect responsibility rules are negligence or fault-based. They require a degree of wrongdoing. For example, in Belgian civil law, when the cause of harm is a thing, the damaged claimant should establish a "defect" understood as an abnormal feature that may be conducive to damage in certain circumstances. In contrast, in French civil law, there is no necessity to establish a defect. Both regimes, however, 
necessitate proof that the keeper of the things exercised effective control over it.

The policy argument is quite convincing that using the assistance of a self-learning and autonomous machine should not be treated differently from employing a human auxiliary, if such assistance leads to harm of a third party ('principle of functional equivalence'). Nevertheless, at least in those jurisdictions, which consider vicarious liability a variant of fault liability, holding the principal liable for the wrongdoing of another, it may be challenging to identify the benchmark against which the operation of non-human helpers will be assessed in order to mirror the misconduct element of human auxiliaries. The potential benchmark should take into account that in many areas of application, nonhuman auxiliaries are safer, that is less likely to cause damage to others than human actors, and the law should at least not discourage their use.

Generally, most of the liability laws assume a human actor. Therefore, robots and other machines are mostly seen as mere tools. This concept has been applied to electronic communications, where automated message systems are attributed to the person on whose behalf the computer was programmed (Article 12 United Nations Convention of the Use of Electronic Communications in 
International Contracts). This evaluation corresponds to the general principle that the employer of a tool should be responsible for the results of its use since the tool has no will of its own. However, the more autonomous robots are, the less they may be seen as mere tools in the hands of the user.

\section{- Strict liability:}

Particularly from the $19^{\text {th }}$ century onwards, legislators often responded to risks brought about by new technologies by introducing strict liability, replacing the notion of responsibility for misconduct with liability irrespective of fault, attached to specific risks linked to some object or activity, which was deemed permissible, though at the expense of a residual risk of harm linked to it. So far, these changes to the law have concerned, for instance, means of transport (such as trains or motor vehicles), energy (such as nuclear power, power lines), or pipelines. Even before that, tort laws often responded to increased risks by shifting the burden of proving fault, making it easier for the victim to succeed if the defendant was in control of particular sources of harm such as animals. or defective immovable.

The landscape of strict liability in Europe is quite varied. Some legal systems are restrictive and have made very limited use 
of such alternative liability regimes (often expanding fault liability instead). Others are more or less generous, while not allowing analogy to individually defined strict liabilities. Some Member States have also introduced a (more or less broad) general rule of strict liability, typically for some 'dangerous activity', which the courts in those jurisdictions interpret quite differently. In some jurisdictions, the keeping of a thing causes strict liability, which is another way to provide for a rather far-reaching deviation from the classic fault requirement.

Existing rules on strict liability for motor vehicles, which can be found in many, but not all EU Member States, may well also be applied to autonomous vehicles or drones, but there are many potential liability breaches.

Strict liability for the operation of computers, software or the like is so far widely unknown in Europe, even though there are some limited examples where countries provide for the liability of the operator of some (typically narrowly defined) computer system, such as databases operated by the state.

The advantage of strict liability for the victim is obvious, as it exempts them from having to prove any misconduct within the defendant's sphere, let alone the causal link between such offense 
and the victim's loss, allowing the victim to focus instead only on whether the risk brought about by the technology materialised by causing them harm. Nevertheless, one has to bear in mind that often-strict liabilities are coupled with liability caps or other restrictions in order to counterbalance the increased risk of liability of those benefiting from the technology. Such caps are often further justified as contributing to making the risk insurable, as strict liability statutes often require adequate insurance cover for the liability risks.

A factor which any legislator considering the introduction of strict liability will have to take into account is the effect that such introduction may have on the improvement of the technology, as some may be more hesitant to actively promote technological research if the risk of liability is considered a preventive. Instead, this allegedly chilling effect of tort law is even stronger as long as the question of liability is entirely unresolved and therefore unpredictable, whereas the introduction of a specific statutory solution at least more or less clearly delimits the risks and contributes to making them insurable. 


\section{- Product liability:}

In principle, the civil and commercial laws of the MENA region are homogenous. This is, among other reasons, due to the influence of Egyptian law. In particular, the Civil Code $(131 / 1948)$ serves as a basis for the development of civil and commercial laws throughout the region. However, product liability laws have only recently been developed and thus were little influenced by the expansion of Egyptian law in the MENA region during the second half of the 20th century. Consequently, regulations governing this area of law are much more heterogenic. This update provides an overview of the product liability regulations that should be considered when trading with Egypt.

Furthermore, for more than 30 years, the principle of strict producer liability for personal injury and damage to consumer property caused by defective products has been an important part of the European consumer protection system. At the same time, the harmonisation of strict liability rules has helped to achieve a level playing field for producers supplying their products to different countries. On the other hand, while all EU Member States have implemented the Product Liability Directive (PLD). liability for defective products is not harmonised entirely. Apart from differences in implementing the directive, Member States also 
continue to preserve alternative paths to compensation in addition to the strict liability of producers for defective products under the PLD.

The PLD is based on the principle that the producer (broadly defined along the distribution channel) is liable for damage caused by the defect in a product they have put into circulation for economic purposes or in the course of their business. Interests protected by the European product liability regime are limited to life and health and consumer property.

The PLD was drawn up on the basis of the technological neutrality principle. According to the latest evaluation of the directive's performance, its regime continues to serve as an effective tool and contributes to enhancing consumer protection, innovation, and product safety. However, some key concepts underpinning the EU regime, as adopted in 1985, are today an inadequate match for the potential risks of autonomous robots and AI. The progressive sophistication of the market and the prevalent penetration of autonomous robots and AI reveal that some key concepts require explanation. This is because the key aspects of the PLD's liability regime have been designed with traditional products and business models in mind - material objects placed on the market by a one-time action of the producer, after which the 
producer does not maintain control over the product. Emerging digital technologies put the existing product liability regime to the test in several respects concerning notions of product, defect and producer.

The scope of the product liability regime rests on the concept of product. For the purposes of the Directive, products are defined as movable objects, even when incorporated into another movable or immovable object, and include electricity. So far, the distinction of products and services has not encountered insurmountable difficulties. However, autonomous robots and especially $\mathrm{Al}$ systems, challenge that clear distinction and raise open questions. In AI systems, products and services permanently interact and a sharp separation between them is unfeasible. It is also questionable whether software is covered by the legal concept of product or product component. It is particularly discussed whether the answer should be different for embedded and non-embedded software, including over-the-air software updates or other data feeds. Regardless, where such updates or other data feeds are provided from outside the EEA, the victim may not have anybody to turn to within the EEA, as there will typically not be an intermediary importer domiciled within the EEA in the case of direct downloads. 
The second key element of the product liability regime is the notion of defect. Defectiveness is assessed based on the safety expectations of an average consumer, taking into account all relevant circumstances. The interconnectivity of products and systems makes it hard to identify defectiveness. Sophisticated AI autonomous systems with self-learning capabilities also raise the question of whether unpredictable deviations in the decisionmaking path can be treated as defects. Even if they constitute a defect, the state-of-the-art defence may apply. Furthermore, the complexity and the opacity of emerging autonomous robots and AI complicate chances for the victim to discover and prove the defect and prove causation.

As the PLD focuses on the moment when the product was put into circulation as the key turning point for the producer's liability, this cuts off claims for anything the producer may subsequently add via some update or upgrade. Moreover, the PLD does not provide for any duties to monitor the products after putting them into circulation. Highly sophisticated AI systems may not be finished products that are put on the market in a traditional way. The producer may retain some degree of control over the product's further development in the form of additions or updates after circulation. At the same time, the producer's control may be limited 
and nonexclusive if the product's operation requires data provided by third parties or collected from the environment, and depends on self-learning process and personalising settings chosen by the user. This dilutes the traditional role of a producer, when a multitude of actors contribute to the design, functioning and use of the AI product/system.

This is related to another limitation of liability - most Member States adopted the so-called development risk defence, which allows the producer to avoid liability if the state of scientific and technical knowledge at the time when he put the product into circulation was not such as to enable the existence of the defect to be discovered (Article 7 PLD). The defence may become much more important practically with regard to sophisticated Al-based products.

It has been mentioned that the PLD regime protects life and health as well as consumer property. With regard to the latter, it is not clear whether it covers damage to data, as data may not be an 'item of property' within the meaning of Article 9 PLD.

\section{- Contributory conduct:}

While balancing liability in light of the victim's own conduct contributing to their harm does not raise new problems in the era of 
emerging digital technologies, one should keep in mind that all challenges listed above with respect to the tortfeasor apply correspondingly to the victim. This is particularly true if the victim was involved in or somehow benefited from the operation of some smart artificially system or other interconnected autonomous robots, e.g. by installing (or failing to install) updates, by modifying default system settings, or by adding their own digital content. Apart from collisions of autonomous vehicles, further obvious examples include the homeowner who fails to properly install and combine multiple components of a smart home system despite adequate instructions. In the former case, two similar risks meet, whereas in the latter the risks of an emerging digital technology have to be weighed against failure to abide by the expected standard of care.

\section{- Prescription:}

While there is a certain trend throughout Europe to reform the laws regarding prescription of tort claims, it is uncomplicated to apply these rules to scenarios involving autonomous robots and AI. Nevertheless, one should be aware that particularly in jurisdictions where the prescription period is comparatively short, the complexities of these technologies, which may delay the factfinding process, may run counter to the interests of the victim by 
cutting off their claim prematurely, before the technology could be identified as the source of her harm.

\section{- Procedural challenges:}

In addition to the problems of substantive tort law already indicated, the application of liability frameworks in practice is also affected by challenges in the field of procedural law. Considering the tendency of case law experience in some Member States to alleviate the burden of proving causation in certain complex matters (such as medical malpractice), one could easily envisage that courts might be similarly supportive of victims of emerging autonomous robots and AI, who have a hard time proving that the technology in question was the actual cause of their harm. Nevertheless, again this is likely to differ from case to case and most certainly from Member State to Member State. As far as purely procedural issues are concerned, there may equally be problems; as well, established procedural law concepts like prima facie evidence may be difficult to apply to situations involving of autonomous robots and AI.

The subsequent differences in the outcome of cases which result from differences in the procedural laws of the Member States 
may be alleviated at least in part by harmonising the rules on the burden of proof.

\section{- Insurance:}

An obligatory insurance scheme for certain categories of autonomous robots and AI has been proposed as a possible solution to the problem of allocating liability for damage caused by such systems (sometimes combined with compensation funds for damage not covered by mandatory insurance policies). Nevertheless, an obligatory insurance scheme cannot be considered the only answer to the problem of how to allocate liability and cannot completely replace clear and fair liability rules. Insurance companies form a part of the completely social ecosystem and need liability rules to protect their own interests in relation to other entities (redress rights).

Additionally, in order to keep emerging autonomous robots and AI as safe as possible and, therefore, trustworthy a duty of care should be affected by insurance as little as possible. However, at the same time, cases of very high or catastrophic risks need to be insured in order to secure compensation for potentially serious damage. 
Therefore, the question relates to whether first party or third party insurance, or a combination of both, should be required or at least recommended and in which cases. Currently, EU law requires obligatory liability (third party) insurance e.g. for the use of motor vehicles, air carriers and aircraft operators, or carriers of passengers by sea. Laws of the Member States require obligatory liability insurance in various other cases, mostly coupled with strict liability schemes, or for practicing certain professions.

New optional insurance policies (e.g. cyber-insurance) are offered to those interested in covering both first- and third-party risks. Generally, the insurance market is quite heterogeneous and can adapt to the requirements of all involved parties. Nevertheless, this heterogeneity, combined with a multiplicity of actors involved in an insurance claim, can lead to high administrative costs both on the side of insurance companies and potential defendants, the lengthy processing of insurance claims, and unpredictability of the final result for the parties involved.

Insurers traditionally use historical claims data to assess risk frequency and severity. In the future, more complex systems, using highly smooth risk profiles based on data analytics, including by analysing data logged or streamed in real time, will be gaining 
ground. In the light of this, the issue of access to data for insurance companies is very pertinent.

The cost efficiency of the claims process is also an important consideration.

\section{- Conclusion:}

When it comes to the unforeseeable but harmful acts of autonomous robotic machines, the legislature should find a balance between a robot's "parent", who might not be guilty, and the "equally blameless victim". To regulate the particular risks of these intelligent robots, a strict liability regime seems appropriate, since the role of human control and, therefore, the possibility of fault will decrease. While the recommended solutions in the US and the EU are similar, the scopes of the discussed liability theories differ from one country to the next. However, all models seem like reasonable to some point. Ultimately, the theory of parental liability might seem the least fitting due to fundamental differences between robots and children. Whereas a kind of vicarious liability or liability for dangerous activities seems most fitting.

However, the theory of dangerous activities might not be a long-term solution either, as the underlying rationale of the theory will become inadequate at some point. Moreover, there are also 
several comparisons when comparing robots to animals. One advantage of treating robots as animals would be the fact that one would not have to consider any special status or rights of the robots, as would be predictable when comparing them to children or employees. In addition, strict liability for animals is based exactly on the unpredictability of animals and the lack of governor owners have, to a certain extent, over erratic animal behavior.

In general, a single broad statute encompassing the liability for all kinds of robots might be "illusory". Instead, the creation of various categories seems more realistic. Categories should be based on several factors: the level of autonomy, learning capabilities, dependence on data (self-contained or external), the operating environment, and the level of risk inherent to the specific robot. Since it is unlikely that users of autonomous systems will be able to assess whether their machine is generally safe or if the model might have been dangerous in the past, the introduction of a centralized agency might be a good solution.

Furthermore, it seems appropriate to limit strict liability to some extent, as traditional liability regimes normally do. Relating to the exceptions for parents and keepers of animals, a robot user could be able to escape liability if he proves that "the dangerous propensities of the robot were reasonably unknown, a fortuitous 
event occurred" or "humans could not prevent the harmful behavior". This would not be possible under the respondent superior liability scheme.

However, a too generous limitation concerning unpredictable behavior would be contradictory to the underlying reason for the establishment of a strict liability regime in the first place. If the same criterion would be used as a limitation to the statute, not much would be gained. Therefore, the liability could be limited to injuries caused by the specific risks of autonomy, which could be described as injuries due to bugs in the software, "an unpredictable selflearning behavior, or defective data".

To conclude, it seems that fault-based liability regimes are not fully capable of determining liability when it comes to the specific risks of autonomous robots. A strict liability regime would, on the other hand, ensure legal certainty and provide compensation for victims. However, the construction of a new doctrine poses challenges for courts and legal scholars across the world. 


\section{References (Bibliography):}

- A. Amkhan, The Concept of Fault in Arab Law of Contract in Arab Law Quarterly, (1994).

- A. Nadoury, Products Liability in Egyptian Law, Washington DC, World Jurists Association, (1997).

- Abdul Ahad Siddiqi, "Implications of using Artificial Intelligence Technology in Modern Warfare”, Communications and Information Technology (IGGIT), International Conference, (2012).

- Ahmed Ibrahim Hassan, 'Origins of the History of Law', University Press, Beirut, (2003).

- Ahmed Ibrahim Mohamed Hussein Mansour, 'Principles of Law', New University press for Publishers, Alexandria, (2006), Theory of Right, New University Publishing press, Alexandria, (2009).

- AJB Sirks, 'Delicts', in D Johnston (ed), The Cambridge Companion to Roman Law, (2015).

- Andrew Tutt, An FDA for algorithms, Administrative Law Review, (2017). 
- Anwar El-Amrousy, 'the natural and legal person in the civil law', Mahmoud Publishing press, Cairo, (2012).

- B. Winiger et al (eds), Digest of European Tort Law III: Essential Cases on Misconduct (2018).

- B. Winiger et al, Digest of European Tort Law I: Essential Cases on Natural Causation, (2007).

- BA. Koch, '15 Years of Tort Law in Europe - 15 Years of European Tort Law?', in; E. Karner, B. Steininger (eds), European Tort Law, (2016).

- BA. Koch/H Koziol, 'Comparative Conclusions', in BA. Koch/H Koziol, Unification of Tort Law: Strict Liability, (2002).

- Balkin, Jack. The Three Law of Robotics in the Age of Big Data, Ohio State Law Journal, Vol. 78, (2017), Forthcoming, Yale Law School, Public Law Research Paper No.592. https;//ssrn.com/abstract $=2890965$

- Bertolini, RoboLaw: Why and how to regulate robotics, Robohub, an article from 29 October 2014. http://robohub.org/robolaw-why-and-how-to-regulate$\underline{\text { robotics }}$ 
- Bottalico Santosousso, "Autonomous System and the law: Why Intelligence Matters", (2017).

- Chopra \& White. A legal theory for autonomous artificial agents, University of Michigan Press, (2011).

- Christian Von Bar et el, Principles, Definitions and Model Rules of European Private Law, Draft Common Frame of Reference (DCFR), outline Edition, (2009), sellier. European law publishers $\mathrm{GmbH}$, Munich, Germany.

- Curtis Karnow, The opinion of machines, Bepress, The Selected Work of Curtis Karnow, (2017).

- Daly Archer. Privacy in Automation: An Appraisal of the Emerging Australian Approach. Computer Law \& Security Review, (2019).

- Dan Dobbs, The Law of Torts, 3rd edition, (2001).

- David. Mindell, Our robots, ourselves: Robotics and the myths of autonomy, (2015).

- Draft AI ethics guidelines, European Commission, December 2019. https://ec.europa.eu/futurium/en/ai-alliance$\underline{\text { consultation }}$ 
- Elbert DeJong, Regulating Uncertain Risks, in an Innovative Society: A Liability Law Perspective, (2013).

- El-Sanhuri: Al-waseet in Civil code, (2003).

- Ethem Alpaydin, Machine Learning, Wiley Interdisciplinary Reviews: Computational Statistics, 3,3 (2011).

- EU Directive 85/374/EEC on liability for defective products. https://eurlex.europa.eu/eli/dir/1985/374/oj

- European Commission, Study on emerging issues of data ownership, interoperability, (re) usability and access to data, and liability, (2018). https://wwwcdn.law.stanford.edu/wpcontent/uploads/2019/02/opitz_wp43.pdf

- European coordinated plan on artificial intelligence, press release, Council of the EU, 18 February 2019. https://ec.europa.eu/knowledge4policy/publication/coordinate d-plan-artificial-intelligence-com2018-795-final_en

- European Parliament, Resolution of 16 February 2017 with recommendations to the Commission on Civil Law Rules on Robotics, (2013/2017(INL)). http://www.europarl.europa.eu/

- F. Pütz et al, 'Reasonable, Adequate and Efficient Allocation of Liability Costs for Automated Vehicles: A Case Study of 
the German Liability and Insurance Framework', European Journal of Risk Regulation, (2018).

- Filipe Alexandre, The Legal Status of Artificially Intelligent Robots, Tilburg University, (2017).

- George Bekey, Autonomous Robots, from Biological Inspiration to Implementation and Control, (2005).

- George Cole, Tort liability for artificial intelligence and expert systems, Computer/Law Journal, (1990).

- Gerhard Wagner, Strict Liability in European Private Law, 2nd edition, (2011).

- Goodfellow et al., Deep Learning, (2016).

- H. Amir, AR. Amir, Civil Liability, Tortious and Contractual, Knowlege House, Cairo, (1979).

- H. Koziol, 'Comparative Conclusions', in H Koziol (ed), Basic Questions of Tort Law from a Comparative Perspective,(2015).

- Hammam Muhammad Mahmoud, 'Introduction to Law, Theory of Law, First Edition', Al-Halabi Legal Rights Publications, Beirut, (2010). 
- Harry Surden, Machine Learning, and Law, the George Washington Law Review, (2014).

- Hassan Kira, 'Introduction to Law - Law in General', Maarif Foundation press, Cairo, (2014).

- Horst Eidenmüller: The Rise of Robots and the Law of Humans, Oxford Legal Studies Research Paper No. 27(2017). http://dx.doi.org/10.2139/ssrn.2747994

- Howard L. Stovall, Prooduct Liabilty Law In Egypt, An Overview of some Civil and Commercial Code Rules, (2005). https://docplayer.net/95650913-Artificial-intelligence-andthe-external-element-of-the-crime.html \& https://www.andchange.com/transforming-changemanagement-artificial-intelligence-ai/

- I. Gilead, M. Green, BA. Koch, Proportional Liability: Analytical and Comparative Perspectives,(2013). https://www.techylib.com/en/view/worrisomebelgian/suggest ion for a green paper on legal issues in robotics

- International Law Commission: Survey on Liability Regimes Relevant to the Topic of International Liability for Injurious Consequences Arising out of Acts not Prohibited by 
International Law: Study Prepared by the Secretariat (UN Doc A/CN.4/471) in Yearbook of the International Law Commission II.1 (1995).

- Jack Balkin, The Path of Robotics Law, Vol.6, California Law Review Circuit, (2015).

- John Weaver, Robots Are People Too, (2014). https://papers.ssrn.com/sol3/papers.cfm?abstract $\mathrm{id}=2941001$

- K. Zweigert, H. Kötz, Legal Operations Management, edition by RP Falta and C Dueblin, Berlin: Springer (2016).

- Karen Turner, 'Meet "Ross", the newly hired legal robot', Washington Post, (Washington, 16 May 2016). /66www.washingtonpost.com/news/innovations/wp/2016/16/ meet-ross-the-newly-hired-legal-robot/?utm term=.6d6 $\underline{\mathrm{dc} 645330}$

- Kenneth Abraham, The Forms and Functions of Tort Law (Concepts and Insights), Publisher Foundation Press, $\left(5^{\text {th }}\right.$ edition), (2017).

- M Bussan, IV. Palmer, Pure Economic Loss in Europe (2003). 
- M. Baretić in E. Karner, K. Oliphant, B. Steininger, European Tort Law: Basic Texts ( $2^{\text {nd }}$ edition), (2019).

- M. Bussani, Palmer, 'The Liability Regime of Europe'. (2002).

- M. Martín-Casals (ed), The Devoloment Liability in Relation to Technological Change, (2010).

- Majdi Harajah, 'Persons and Monies in Civil Law', Mahmoud Publishing press, Cairo, (2012).

- Mansour Mustafa Mansour, 'Principles of Law', Dar AlNahda Al-Arabia, Cairo, (1972).

- Mark Geistfeld, 'A Roadmap for Autonomous Vehicles: State Tort Liability, Automobile Insurance, and Federal Safety Regulation', (2017).

- Mathew Scherer, Regulating Artificial Intelligence Systems: Risks, Challenges, Competencies, and Strategies, (2016).

- Matilda Karlsson, Artificial Intelligence and the External Element of the Crime, An Analysis of the Liability Problem, (2017). 
- Matteo Santoro, Dante Marino, Guglielmo Tamburrini, Learning robots interacting with humans: from epistemic risk to responsibility, AI \& Society, Vol 22, (2008).

- Mohamed Abdel Al-Majid al-Mughrabi, 'History of Law', Modern Book Foundation, Tripoli - Lebanon, (1987).

- Muhammad Hassan Qasim, 'Introduction to Law Study Theory of Law - Part 1, Theory of Right, Part Two', AlHalabi Human Rights Publications, Beirut, (2012).

- Nationality law of Japan (1950-2008).2019. http://www.moj.go.jp/ENGLISH/information/tnl-01.html

- Nick Bostrom, Superintelligence: Paths, Dangers, Strategies (OUP) (2014).

- Nikolova Rodionov, Impact of Globalization on Innovation Project Risk Estimation. European Research Studies Journal, 20(2B), (2019).

- Nils Nilsson, The Quest for Artificial Intelligence (Cambridge University Press, 2010).

- P. Machnikowski, 'Conclusions', in P. Machnikowski (ed), European Product Liability: An Analysis of the State of the Art in the Era of New Technologies, (2016). 
- Patrick Hubbard, Sophisticated Robots: Balancing Liability, Regulation, and Innovation, Florida Law Review, Vol.66 (2015).

- Paulius Cerka et al., Liability for damages caused by artificial intelligence, 31 Computer Law \& Security Review, (2015). $\underline{\text { www.sciencedirect.com }}$

- Peter Asaro, The Liability Problem for Autonomous Artificial Agents, (2019).

- Peter Hay, US-Amerikanisches Recht, (2015).

- Peter Norving and Stuart Russell, Artificial Intelligence: A Modern Approach, (3rd edition,) Press education Limited, (2016).

- Peter Stone and others, 'Artificial Intelligence and Life in 2030' one hundred Year Study on Artificial Intelligence: Report of the 2015-2016 Study Panel, (Research Report, and Stanford University 2016). http://ai100. Stanford.edu/2016report

- R. Abbott, "The Reasonable Computer: Disrupting the Paradigm of Tort Liability', 86 Geo. Wash. L. Rev. 1 (2018). 
- Richard Kelley et al., Liability in Robotics: An International Perspective on Robots as Animals, 24 Advanced Robotics, (2010).

- Richard Sherman, 'The Surge of Artificial Intelligence: Time To Re-examine Ourselves. Implications: why Create Artificial Intelligence? (1998) http://www.units.muohio.edu/psybersite/cyberspace/aisurge/i mplication.shtml

- Ryan Abbott, The Reasonable Computer: Disrupting the Paradigm of Tort Liability, The George Washington Law Review, REV.1 (2018).

- Ryan Calo, "Robotic and the Lessons of Cyberlaw", California Law Review, (2015).

- Ryan Calo, Michael Froomkin, Ian Kerr, Robot Law, (2016).

- S. Galand-Carval, 'Comparative Report on Liability for Damage Caused by Others', in; J. Spier (ed), Unification of Tort Law: Liability for Damage Caused by Others, (2003).

- Saudi Nationality System, (2019). http://www.moi.gov.sa/wps/wcm/connect/EN_Saudi_Nationa lit system.pdf 
- Shaheen Ahmed, Saudi women defy a ban to register for polls, Gulf news, (2018). http://gulfnews.com/news/gulf/saudi-arabia/saudi-womendefy-ban-to-register-for-polls-1799161

- Stuart Russell, Peter Norvig, Artificial Intelligence, A Modern Approach, $3^{\text {rd }}$ edition, (2009).

- Suleiman Morcos, 'Introduction to Legal Theory', Second Edition, without a publishing press, (1974).

- T. Khattab, Civil Law in Egypt and its Laws, edition by $\mathrm{N}$ Bernard-Maugiron and B Dupret, Leiden: Brill, (2002).

- Tawfiq Hassan Faraj, 'Introduction to Legal Theory', University Culture Foundation, Cairo, (1977).

- Thomas Hobbes, 'Of Persons, Authors and Things Personated', chapter. XVI, Leviathan on the Matter, Form and Power of Common Wealth Ecclesiastical and Civil, London, 1651. https://www.ttu.ee/public/m/martmurdvee/EconPsy/6/Hobbes Thomas 1660 The Leviathan.pdf

- U. Magnus, 'Why is US Tort Law so Different?', JETL, (2010). 
- U.S. Chamber Release Artificial Intelligence Principles. https://www.uschamber.com/sites/default/files/chamber_ai p p rinciples - general.pdf

- Ugo Pagallo, a legal journey in robotics, AI \& Society, (2011).

- Ugo Pagallo, the Laws of Robots: Crimes, Contracts, and Torts, (2013).

- W. Buckland, A. McNair, Roman Law and Common Law, (1952).

- W. van Boom, H. Koziol, Ch. Witting, Pure Economic Loss (2004).

- Woodrow Barfield, Liability for Autonomous and Artificially Intelligent Robots, Duke University, (2018).

- Yoav Shoham, why knowledge Representing Matters, 59 COMM. ACM. (2016).

- http://www.units.muohio.edu/psybersite/cyberspace/aisurge/i mplication.shtml

- www.washingtonpost.com/news/innovations/wp/2016/16/me et-ross-the-newly-hired-legal-robot/?utm term=.6d6 $\underline{\mathrm{dc} 645330}$ 
- https://ec.europa.eu/knowledge4policy/publication/coordinate d-plan-artificial-intelligence-com2018-795-final en

- https://eur-lex.europa.eu/eli/dir/1985/374/oj

- $\quad$ https://www-cdn.law.stanford.edu/wpcontent/uploads/2019/02/opitz_wp43.pdf

- https://papers.ssrn.com/sol3/papers.cfm?abstract id=2941001

- http://en.m.wikipedia.org/wiki/Principles_of_European_Cont ract_Law

- $\quad$ https://lexuniversal.com/en/news/20778

- https://www.mondaq.com/contracts-and-commerciallaw/778650/compensation-according-to-egyptian-laws

- $\quad$ www.wipo.int/wipolex/en/text.jsp?file $\mathrm{id}=312041$

- $\quad$ www.wipo.int/edocs/lexdocs/laws/en/ eg/eg053en.pdf 